\title{
Contributing Factors to Older Teen Mothers' Academic Success as Very Young Mothers
}

\author{
Jennifer Hernandez ${ }^{1} \&$ Hazza M. Abu Rabia ${ }^{2}$ \\ ${ }^{1}$ University of Saint Joseph, USA \\ ${ }^{2}$ University of Hartford, USA \\ Correspondence: Hazza M. Abu Rabia, University of Hartford, USA
}

Received: June 23, 2017

Accepted: July 27, 2017

Online Published: August 1, 2017

doi:10.5430/ijhe.v6n4p104

URL: https://doi.org/10.5430/ijhe.v6n4p104

\begin{abstract}
This qualitative study explores the factors contributed to 13 older teen mothers' academic success as very young mothers. The participants were older teen mothers who were pregnant and gave birth at the age of 16 years old or younger, and who have achieved a college degree from an accredited college or university while they raised their child(ren). In depth interviews were employed to document and analyze older teen mother experiences. One-on-one interviews with the participants revealed multiple factors assisted older teen mothers' academic success, including family and other individuals support, teachers, early school attendance, personal drive, and responsibilities. While further research is needed, these findings suggest that developing holistic services for teen mothers is needed to assist in developing future academic success. A holistic approach includes mind, body and spirit (Arsenian, n.d.). These recommended services could be developed within existing programs and should include activities to promote self-awareness, health and some form of exploration of values, faith and family.
\end{abstract}

Keywords: Academic success, Teen mothers, Dispositional Optimism, Older teen mothers

\section{Introduction}

National efforts to prevent teenage pregnancy have contributed to steady declines in the rate of pregnancy for teens (Lindberg LD, Santelli JS, Desai, S., 2007-12). In 2013, the birth rate for women ages 15 to 19 was 18.6 among whites, 39.0 among African Americans, and 41.7 among Hispanic. Despite the decrease in teen birthing rates 275,000 babies were born to adolescent mothers in the United States in 2013 (Hamilton, B. E., Martin, J. A., Osterman, M. J. K., \& Curtin, S. C. 2014).

Adolescents who decide to parent a child at a young age experience accelerated transitions into adulthood and without cautiousness place themselves in reoccurring historical trauma as well as put their children at risk of adverse outcomes. Becoming a teen parent increases young women's risk of academic dropout, decreases their educational attainment, and limits their development of employment skills (Hoffman and Maynard 2008). Early childbirth contributes to complex challenges that impact the entire family. Parental roles shift from parenting an adolescent to parenting a parent who is an adolescent. This complex shift in roles is challenging to navigate without strong supports who themselves have an in-depth understanding of human development. Additionally, concerning is that within this family unit the siblings of adolescent parents are a greater risk of engaging in high risk behaviors and therefore amplifies further risk factors (East, P. L., \& Jacobson, L. J. (2001).

The choice to parent for a teen mother does share great responsibilities far beyond the role of early parenting. The literature is rich with information examining the disparities and barriers that teen mothers face. However, what is often left with limited discussion and examination is of those teen mothers who choice to parent regardless of external support or direction and do so with extraordinary outcomes. Teen mothers are not new members to society. In 2010, fewer teen pregnancies were reported then in the mid 1940's (CDC/NCHS, National Vital Statistics System, 2010). However, today with the influences of social media and television programing the perception of teen parenting is complicated. The first perception is often of a rebellious teenager encountering in defiant sexual behaviors or experimenting in perilous behaviors. The teenage years are developmentally complex and provide the teenager with many life situations to navigate that they are not intellectually, physically and emotional developmentally prepared for. Teenage parents have an added responsibility of entering into parental roles that they are unprepared for. Additionally, often family members and providers i.e. medical professionals and academic 
supports develop and support the teen mothers via their own lens of values around the choice to parent as a teenager. This too often leave those in the teen mothers supports systems failing to fully understand the complexity of developmental contradictions' the teenage parent is attempting to navigate through.

\section{Literature Review}

Nationally, the United States government has spent approximately $\$ 10.9$ billion annually in costs related to teen childbearing (National Campaign to Prevent Teen and Unplanned Pregnancy [NCPTUP], 2011). Programs throughout the country exist to support adolescent mothers via varied approaches. School based programs have been implemented to promote secondary school retention and completion for mothers as well as to provide support for childcare (Kalil \& Ziol-Guest, 2008). Healthcare organizations work with teen mothers in preparing for childbirth, in providing health education, and in teaching prevention. Additionally, human service agencies form linkages to health and educational systems in order to provide services to teen mothers (Office of Adolescent Health, 2014).

Despite the support programs provided to the teen mothers, their lives are complicated. Academic success is a significant challenge for these young mothers as they have to parent and remain in school simultaneously to balance their lives with the norms of adolescence (Spear, 2001). The idea of going to school and acting your age and coming home to parent is a complicated idea for the adolescent mind, let alone the adolescent mind that has experienced trauma. Arguably the act of childbirth itself can be viewed as a traumatic experience, therefore compounding the complexity of the adolescents' mothers' life trajectory. Teen pregnancy has been commonly linked to early traumatic childhood experiences (Hoffman \&Maynard, 2008). Traumatic childhood experiences can adversely impact educational and economic outcomes for young mothers and their children. Young women who become mothers during their early teen years are more likely to have experienced family and neighborhood violence, as well as early nonconsensual sex (Leiderman \& Almo, 2001). Likewise, teen mothers are more probable to be dependent on substances as a means to self-medicate and cope with previous trauma (Hillis, S. D., Anda, R. F., Dub, S. R., Felitti, V. J., Marchbanks, P. A., \& Marks, J. S. 2004). It has also been recorded that teen mothers disproportionally have children who become teen parents themselves (Schuyler Center for Analysis and Advocacy, 2008). Moreover, these children have poor educational attainment and are more likely to become incarcerated. However, Taylor (2012) has suggested that more successful teen mothers display dispositional optimism (Taylor, Larson-Rife, Conger, Widaman, \& Cutrona, 2010; Taylor et al., 2012).

In a study that focused on Mexican and African single mothers' Taylor (2012) studied mothers experiencing economic stress, life stressors, and maternal optimism in single adolescents. These studies identified optimism as an important contributor towards the mothers' ability to adapt and cope with life stressors. Taylor's (2012) research was guided by the Family Stress Model (FSM), a paradigm that examined dispositional optimism as a characteristic that aids in decreasing perceptions of stressors and a mothers' ability to cope (Taylor et al., 2010). Additionally, important to this research is the linkage that early interventions in the mothers' lives may have contributed to the psychological wellbeing of the mothers (Taylor et al.,2010; 2012). Positive relationships with supports such as teachers, nurses, social workers and other teen mothers influence optimistic views of their future and empower teen mothers to strive for better life outcomes then they have experienced (Perrin \& Dorman 2003). Single mothers with more positive views of their life circumstances are more likely to have high self-esteem, stronger parenting skills, greater social competence, and children with higher cognitive abilities. Whereas teen mothers who lack positive views of their future or have negative perceptions of their future are more likely to have experienced challenges in parenting skills (SmithBattle, 2007) attain poor academic achievement for themselves and their children and struggle with the development of relationships (Breedlove, 2005; SmithBattle, 2003).

\section{Methodology and Sampling}

This qualitative study employed in depth interviews to explore older teen mothers' reports regarding the factors contributed to their academic success when raising their child(ren). Snowball sampling provided connections to other older teen mothers who themselves may not have openly responded to a random request for an interview. The participants did not all intimately know each other. However, several linkages were made within professional networks that expanded the researcher's ability to interview this unique population of academically successful teen mothers.

The population for this qualitative action research study were 13 older teen mothers from varied communities who have obtained a college degree from an accredited college or university. The sample criteria for selection included: (a) older teen mothers who gave birth prior to age sixteen and raised their child(ren) and (b) have a degree from an accredited college or university. Preference was given to participants who were the youngest at time of delivery. Consideration was also given to participants across culturally and economically diverse backgrounds to maximize 
variation. Moreover, another criterion that influenced the selection was examining the youngest participants who have obtained the highest degree to achieve the broadest representation.

\section{Limitations of the Study}

Creswell (2009) defined limitations as potential weaknesses or problems in the study that can be identified by the researcher. There are several potential limitations in this study. First, older teen mothers who have college degrees often are not forthcoming about their history as teen mothers due to an understanding of the stigma (SmithBattle, 2007) associated with being a teen mother. A second limitation may come from the sample, whereby women who know one another may have a greater comfort level in inviting peers into the study. This factor could potentially limit the diversity of the sample, as well as contribute to groupthink.

The third limitation could be that the researcher's questions and the interview guide were developed by the contributions of narrative and self-authorship of the older teen mothers in this research. There is also the assumption that optimism represents an influential characteristic that changed views and impacted their movement towards academic success. A forth limitation may be that these older teen mothers do not view programming as supports to teen mothers as influential to their academic success. Finally, generalizing the findings to those older teen mothers' experiences outside one geographical region may prove to be problematic. Thus, geography may serve as a limitation to the study.

\section{Results and Discussions}

\subsection{Emergent Themes}

The analysis of the study results led to the following five themes: early school attendance, family and other individuals' support, teachers' involvement, personal drive, and personal responsibilities. Each theme was developed based on the responses of the participants.

\subsection{Early School Attendance}

Eleven out of the 13 older teen mothers reported early school attendance contributed to their ability to achieve academic success. Despite reports of negative environmental influences 11 out of 13 young mothers were able to report recalling consistency in early school attendance through the fifth grade. Particular to this study, several participants responded by sharing their perception of early academic experiences.

For example: Dawn who was raised by a single mother reported, "School was a place you went to. It was not something we had a choice to do. I had to go. Even though my mother did not know English she wants so much for me and my siblings to have more. So, we went." Carmen who was also raised by a single mother reported challenges in having to prepare herself for school independently "It did not matter I went to school. I don't know when really, I understood that I was making the decision consciously to go without my mother's influence but I just knew, get up get dressed and go to school. Maybe it was a sense of normal when I was there. Nobody really knew what I was dealing with so maybe that was the drive I gave myself even as a little girl that school was a way out." Star who was also raised by a single mother reported, "My mother did not know how to read, but the expectation was I went to school. I wasn't the greatest student or the worst. I was there though. It was not even a question." Lela reported her perceptions of her early academic experiences. "Not going to school was not even an option. I mean don't get me wrong later after junior high school I started skipping but before then there was no way. Even when my parents were high I had to go to school. For me it was an escape anyway." Missy continued, "I don't know if it was cultural but there was no way I wasn't getting to school. My parents were working a lot and staying home wasn't an option." Jemma stated that her "mother was a strong woman. She was a young mother too and never was able to graduate. So, I think for her she was "no way you are not going to school", so elementary school I was all over that. My dad felt the same no questions. We were poor didn't have a lot of clothes and stuff but we went. We got breakfast and lunch so that mattered. I was always trying to get good attendance awards."

Sarah, who was also raised in a dual parent household, reflected on her early years as "normal", and as she responded appeared almost perplexed that a child in elementary school would not attend regularly. "I wasn't an above average student but I was fair. I went to school and did activities. It was all pretty normal."

\subsection{Family and other Individuals Influence}

Nine out of the 13 older teen mothers reported family influence contributed to their ability to achieve academic success. Jemma reported on the influences that contributed to her academic success with her sisters' contributions. "I never felt smart enough to go to school. I was all over the place getting high doing whatever. But my sisters" they had this drive. I mean my oldest sister she would be on me all the time, "what are you doing with your life", "is this 
how you want your kids to see you", she was real about what she wanted for me but she also was gracious enough to provide me with direction how to do and get to school. We go to school together now. It is really amazing."

Carmen's reports included her recall of one of her mother's sister. "It was kind of interesting, here my mother was an addict and her sister, my aunt. She's going for her $\mathrm{PhD}$, in forensics and microbiology. Very smart woman. She is the only one in the family with college. She was never pushing education or anything. But when I saw her I remember thinking there was something different about her."

Star's reports of family influence in academic success were described as an unspoken expectation in her early life. "My mother never said anything about me going to college I guess I just assumed I would. She gave me the impression that I needed to be different from my siblings so, her unspoken influence was enough pressure for me to move on in school." Lela, who described much of her early childhood as challenging reported that though her parents were not aware of their influences to further her education, she reported that they actually did have an impact. This motivated her. "I was going to be everything that they weren't. My kids would never go through or see the things that I saw or went through."

\subsection{Personal Drive}

Ten out of the 13 older teen mothers reported personal drive contributed to their ability to achieve academic success. Lela reported her personal need to succeed regardless of what she considered were the negative norms and prevailing academic views regarding teenage pregnancy. "I just think that I expected that (school) for myself. In a way, it was like to be different or defy. Because when I got pregnant the second time, I was very emotional. Because statistics say one out of whatever, teenage moms or $50 \%$ of teenage moms will get pregnant with their second child two years later. So, I was like...devastated...I was like, "Oh my God, I'm part of the statistics now. I was like, "Oh, but I have to finish."

Jemma had many challenges that contributed to her ability to succeed in school as a young mother. However, after Jemma began to experience college she began to become more invested in higher education. "I was a 13-year-old mother. Now I have my degree. I cannot wait to go get another just to prove to everyone who saw me as nobody that I am a somebody."

Carmen who has a Master's in Social Work shared some of her thoughts as to what would be next for her. "I'm still figuring out what I want to do with the degree that I have. I'm still thinking of what I want to do, if I want to get licensed. I also love play therapy, so I may want to get a certification in play therapy. I can get my own practice. I love school. I love learning. I've learned so much. I've grown so much going to school it gets like I need to keep going. I just have to."

Sarah who came from a very supportive family shared her personal need to achieve academic success. "College was expected. I knew that. But wanting to and needing to be successful was an internal drive. I refused to let my past experiences stop me from achieving."

Missy continued, "I want people to know yes I was young and made it." Nancy shared "I would look around me at others without college and knew I would be different. I had to just keep going." Esther added, "part of my drive was to prove people wrong." Lysa continued, "I needed to show people I was strong." Star shared, I got one degree and then another and am still thinking I may go back. I have this need to learn and grow it helps me stand taller."

\subsection{Responsibility}

Eleven out of the 13 older teen mothers reported the added responsibility after pregnancy contributed to their ability to achieve academic success. The women in this study represent the youngest of teen mothers. Each participant was sixteen or younger when she delivered her baby. Academically, they were in their early years of high school during the time of their pregnancy. The responsibility of having a child contributed to their dispositional optimism and their ability to achieve academic success.

Lela, "I always knew I wanted to go college, but I questioned how at first, after having my first child...going to school was a must. Right after I gave birth, I went to night school and I got my diploma. I always knew I was going. I knew I didn't want to use my daughter as a crutch or an excuse not to go and the reason I couldn't go... Now I had to be that example for her so I went back to night school as soon as I gave birth to her and I just knew I was going to do it. I said, "I'm going to go to business school and from there I'm going to go to college. I'm not going to stop until I get my Bachelor's." Cat reported mixed feelings about her motivation. "Most people would say their kids. For me I thought if I can be strong my baby would be too. I wanted to be someone he looked up to. So, I guess he had an influence." 
Nancy furthered the conversation, "when I found out I was pregnant I thought for a minute my world was over. I couldn't do it all. Going to school day to day in a regular setting was not something I could wrap my head around. But when I found out I was pregnant, it took me some time but what I knew was that I was going to make sure that my child could look up to me as a mother, no matter what. I knew that what I had seen and all that was not going to be a part of my child's story. So, I guess you can say I had a motivator." Lysa reported, "having a baby young you have to kind of think about what direction life can take. I decided that I would be a mother that made my child proud."

Jemma reflected on her childhood, "I saw a lot of really bad things, gangs, drugs etc. At first when I had my baby I was so young I could not wrap my head around school. I messed up for a while and then when it all clicked I looked at my kids and was like ok get it together. So it wasn't right away but I have a responsibility to show them the world and teach them. So they are my motivators." Star, "I just knew if I wanted more for my life and my child's I needed to get away from what was in front of me. I knew somehow education was going to give us more then what we had."

\subsection{Teachers Influence}

Six out of the 13 older teen mothers reported positive influences from a teacher contributed to their ability to achieve academic success. Jemma reported that the personal character of the adult matter in her journey to academic success. "I remember an English teacher who was amazing, or a math teacher who was patient. That made a difference for me." Esther shared, "I think there were a few professors that really were great. I mean one even talked with me about ideas to help my daughter develop and read and just stuff about kids. Another I remember was like so on me about writing and learning new words. He was like, you write naturally pretty well, so let's expand your vocabulary. He would correct my papers and add new words to what I wrote. It was cool." Carmen shared that she was glad she kept herself enrolled in school. "I was glad I stayed in school in high school. You know it wasn't easy and I really didn't share everything that was going on. But I had a teacher who always treated me with respect. She didn't look down at me. She talked to me like I mattered."

Star shared "I am grateful to a few teachers who were real with me. I was confused and didn't really know all what I was going to do in life. I was a mess sometimes, but along the way there were a few that understood what I was experiencing. They got were I came from. They weren't like saying, "oh I know you are Latina and poor", they were just empathetic and encouraging." Lysa, when I was little I remember this teacher she was a very colorful woman.

She dressed so different from everyone else. She was different I think. I remember a class when I was so lost in social studies. She was so helpful and understanding. She spoke to me with concern and like this sense of-I don't know-I guess then I didn't know but I do now that it was respect." Cat concluded the discussion. "If you can imagine my kindergarten teacher was the biggest influence in my school life. I loved being there. I was able to pretend. She made the classroom colorful. She praised me for talking. That is funny cause at home I was always told to stay quiet".

\section{Conclusion and Recommendations}

Early school attendance is consistent with the literature and impacted future educational outcomes (Chang \& Romero, 2008). Early academic success is not only defined through academic grades, but also included aspects of social and emotional interactions, development of language and cognitive development and consistency of attendance (Sektnan, McCleeland, Acock, \& Morrison, 2010). Moreover, those who attend school consistently in grade school have a greater likelihood to be proficient in reading. Successful early reading also provides for greater likelihood to achieve academic success.

For these older teen mothers, reports of successful early school attendance varied in reasoning. The role that school played was that of childcare, nutritional source via school meal program, and commitment to academic achievement. In some instances, single parent households had no other option for childcare and therefore viewed school as a safe means of supervision. School also, provided two meals, breakfast and lunch which contributed to relieving stressors about financially supporting additional meals. Finally, of these older teen mothers, there were reports of the expectation of school attendance within the family structure. These families had an early commitment to academic achievement. For some the early commitment was reported as a cultural norm of immigrant families. Spears, (2011) discussed the complexity of balancing the role of parenting and academic obtainment within the role of adolescents.

Other individuals influence contributed to the older teen mothers' ability to achieve academic success. Dawn reported two relationships that she considered important for her motivation to achieve academic success. She stated that there was a classmate as well as a woman who interviewed her for nursing school. "That lady from the Caribbean she had a lot of children and she was in school as I was. We would study together. She was an encourager. 
The woman that interviewed me was also supportive. She would find me needed supports to help me stay in school." Mia, who reported minimal family supports, saw the simplicity of a friend's one time encouragement as a means to further her academic pursuits. "She just asked me why I am not going further then the CNA (Certified Nursing Assistant). She said it in a real question and I remember thinking-yeah, she's right. And so, I applied to nursing school." As Carmen started working, she noted that individuals who were younger than she was had college degrees. She reported that as she observed and listened to conversations of encouragement to go to school she was moved to further her education. "I loved what I was doing and I would look around, this one had a degree that one....and they would all ask me why I wasn't in school. That made me want to go." Cat also shared the simplicities of her experience with someone who moved her toward furthering her education. "This lady at Adult Education she told me about college... so I went..." Sarah reported her connection with a friend from high school with whom she remains in touch. "We both graduated, she went to college, I went to college and we've stayed very close. She is still my very best friend. She's one of my biggest support systems." For Jemma, interactions with other students kept her optimistic about her educational outcomes. "I would be in class and think really, ok so I can contribute to this or that idea. I would hear other students and think I get it. Then I would be motivated to keep going. I loved group work, sometimes cause then you really got to get to know others and we could help each other."

Varied forms of relationships contributed to the older teen mothers' academic success. This finding is consistent with the literature that indicates supportive relationships are powerful influences on one's outlook on life (House, 1981). For these older teen mothers, their reports included varied relationships with others outside their identified families, family relationships and reports of positive and negative influences from teachers. Additionally, important was the identification of influences that were provided for these older teen mothers that included random encounters with individuals whom they did not know. These individuals included people they met once in passing or their observation of another family they knew through peers or neighbors. Influences in one's ability to develop dispositional optimism can be randomly received in the most unexpected situations (Krizan \& Windschitl, 2007). The findings, specifically reported by the older teen mothers as important to their ability to develop optimism and achieve academic success, are concurrent with the literature that supports promotion of academic success. Teen mothers who have experienced early traumas can overcome those adversities and achieve academic success. Relationships though reported in this study, vary in meaning. However, noted, the reported relationships were instrumental in these older young mothers' dispositional optimism and academic success. Furthermore, the literature supports that regardless of the longitude of the relationship relational impacts can be assured (Lemberger, Selig, Bowers, \& Rogers, 2014).

Relationships can provide supportive factors for one to develop a direction towards future goals (Camarena, Minor, Melmer, \& Ferrie, 1998). In summation, family support as defined by the participants included individuals they identified as family members. Their supports additionally included unspoken parental expectations that supported academic achievement in their family as well as teachers' influences.

Another factor that contributed to development of perception of self was life experiences (Huan, Yeo, Ang, \& Har Chong, 2006). Older teen mothers reported meaning in their experiences. Though reports included situational challenges, the participants shared the ability to reframe their thinking towards optimistic outcomes. Individuals who are able to cognitively restructure their thinking have profound abilities to cope with even life's challenging events (Lazarus \& Folkman, 1984).

\section{References}

Arsenian, S. (n.d.). The Humanics philosophy of Springfield College. Retrieved from Springfield College: http://www.springfieldcollege.edu

Breedlove, G. (2005). Perceptions of social support from pregnant and parenting teens using community-based doulas. The Journal of Perinatal Education, 14(3), 15-22. https://doi.org/10.1624/105812405X44691

Camarena, P. M., Minor, K., Melmer, T., \& Ferrie, C. (1998). The nature of support of adolescent mothers' life aspirations. Family Relations, 47(2), 129-137. https://doi.org/10.2307/585616

Chang, H.N., \& Romero, M. (2008). Present, Engaged, and Accounted For: The Critical Importance of Addressing Chronic Absence in the Early Grades. National Center for Children in Poverty, Mailman School of Public Health at Columbia University, New York, NY.

East, P. L., \& Jacobson, L. J. (2001). The Younger Siblings of Teenage Mothers: A Follow-Up of Their Pregnancy Risk. Developmental Psychology, 37(2), 254-264. https://doi.org/10.1037/0012-1649.37.2.254

East, P. L., Felice, M. E., \& Morgan, M. C. (1993). Sisters' and Girlfriends' Sexual and Childbearing Behavior: Effects 
on Early Adolescent Girls' Sexual Outcomes. Journal of Marriage and the Family, 55(4), 953-963. https://doi.org/10.2307/352775

Feldman, A.M., \& Matjasko, J. L. (2005). The role of school-based extracurricular activities in adolescent development: A comprehensive review and future directions. Review of Educational Research, 75, 159-210. https://doi.org/10.3102/00346543075002159

Hamilton, B. E., Martin, J. A., Osterman, M. J. K., \& Curtin, S. C. (2014). Births: Preliminary date for 2013. Hyattsville, MD: National Center for Health Statistics.

Hillis, S. D., Anda, R. F., Dub, S. R., Felitti, V. J., Marchbanks, P. A., \& Marks, J. S. (2004). The association between adverse childhood experiences and adolescent pregnancy, long- term psychological consequences, and fetal death. Pediatrics, 113(2). https://doi.org/10.1542/peds.113.2.320

Hoffman, S. D., \& Maynard, R. A. (2008). Kids having kids' Economic casts and social consequences of teen pregnancy (2nd ed.). Washington, D.C.: Urban Institute Press.

Huan, V. S., Yeo, L. S., Ang, R. P., \& Har Chong, W. (2006). The Influences of dispositional optimism and gender on adolescents' perception of academic success. Adolescence, 41(163).

Kalil, A., \& Ziol-Guest, K. M. (2008). Teacher support, school structures, and teenage mothers school engagement. Youth \& Society, 39(4), 524-548. https://doi.org/10.1177/0044118X07301001

Lazarus, R. S., \& Folkman, S. (1984). Stress, appraisal, and coping. New York: Springer.

Leiderman, S., \& Almo, C. (2001). Interpersonal violence and adolescent Pregnancy: Prevalence and implications for practice and policy. Washington, DC: Healthy Teen Network.

Lemberger, M.,Selig, J., Bowers, H., \& Rogers, J. (2015). Effects of the student success skills program on the executive functioning skills, feelings of connectedness, and academic achievement in in a predominantly Hispanic, low-income middle school district. Journal of Counseling and Development, 93, 25-36. https://doi.org/10.1002/j.1556-6676.2015.00178.x

Lindberg LD, Santelli JS, Desai, S. Understanding the Decline in Adolescent Fertility in the United States, 2007-2012. J Adolescent Health. (2016). 1 (7). https://doi.org/10.1016/j.jadohealth.2016.06.024

National Campaign to Prevent Teen and Unplanned Pregnancy. (2011). Counting it up: The public cost of teen childbearing. Retrieved from thenationalccampain.org/costs

Office of Adolescent Health. (2014). http://www.hhs.gov/ash/oah/adolescent-healthtopics/reproductive-health/teen-pregnancy.

Perrin, K\& Dorman, K (2003). Teen Parents and Academic Success. The Journal of the School of Nursing 19(4), 288-293. https://doi.org/10.1177/10598405030190050701

Schuyler Center for Analysis and Advocacy. (2008). Teenage births: Outcomes for young parents and their children. Albany, NY: Author.

Sektnan, M., McClelland, M. M., Acock, A., \& Morrison, F. J. (2010). Relations between early family risk, children's behavioral regulation, and academic achievement. Early Childhood Research Quarterly, 25(4), 464-479. https://doi.org/10.1016/j.ecresq.2010.02.005

SmithBattle, L. (2003). Understanding teenage mothering: Conventional and unconventional wisdom. The Prevention Researcher, 10(3), 1-4.

SmithBattle, L. (2007). Legacies of advantage and disadvantage markers of adulthood among adolescent mothers. Journal of School Nursing, 24(5) 293-300.

Spear, H. J. (2001). Teenage pregnancy: "Having a baby won't affect me that much". Pediatric Nursing, 27(6), 574-580.

Taylor, Z.E., Larson-Rife, D., Conger, R. D., Widaman, K. F., \& Cutrona, C. E. (2010). Life stress, maternal optimism and adolescent competence in single mothers, African American families. Journal of Family Psychology, 24(4), 468-477. https://doi.org/10.1037/a0019870

Taylor, Z.E., Widaman, K. F., Robins, R. W., Jachem, R., Earky, D. R., \& Conger, R. D. (2012). Dispositional optimism: A Psychological resource for Mexican-Origin mothers experiencing economic stress. Journal of Family Psychology, 26(1) 133-139. https://doi.org/10.1037/a0026755

U.S. Department of Public Health, Vital Statistics. (2009). Washington, DC: Government Printing Office. 